\title{
Transmission of infectious salmon anaemia (ISA) through natural secretions and excretions from infected smolts of Atlantic salmon Salmo salar during their presymptomatic phase
}

\author{
Geir K. Totland ${ }^{1, *}$, Brit K. Hjeltnes ${ }^{2}$, Per R. Flood ${ }^{1}$ \\ ${ }^{1}$ University of Bergen, Institute of Zoology, Allegt. 41, N-5007 Bergen, Norway \\ ${ }^{2}$ Institute of Marine Research, Department of Aquaculture, N-5024 Bergen, Norway
}

\begin{abstract}
Short-term ( $48 \mathrm{~h}$ ) exposure of healthy Atlantic salmon Salmo salar L. smolts to infectious salmon anemia (ISA)-inoculated cohort smolts showed that the disease was transmitted with near $100 \%$ mortality from Day 7 post-inoculation and onwards. This is more than a week before the inoculated fish show any clinical signs and long before the typical petechial bleedings occur. A bloodborne transmission of the disease is therefore unlikely. Skin mucus, faeces, urine and blood, isolated from ISA-inoculated smolt, transmitted the disease to healthy cohort smolt with variable efficiency depending on how the inoculum was administered. All the sources were infectious and transmitted the disease with high efficiency when injected intraperitoneally (i.p.) into cohort smolt. After i.p. injection, skin mucus had somewhat lower infectivity than blood homogenates. Furthermore, in some experiments application of skin mucus to the gills was as efficient as i.p. injection for transmission of the disease. When introduced into the stomach none of the inocula caused ISA. Coprophagy thus seems to be ineffective in the transmission of ISA under laboratory conditions. Skin mucus from non-inoculated cohabitants exposed to ISA-inoculated smolts for $2 \mathrm{~d}$ transmitted the disease with close to $100 \%$ efficiency to healthy cohort smolts when injected i.p. This indicates that the infectious agent is waterborne and absorbed by the skin mucus rather than being secreted with the skin mucus. Since healthy smolts have an intact skin barrier, proximity to inoculation directly to the vascular bed seems unlikely. An ultrastructural study of 10 different organs, all in close proximity to the secretions/excretions, revealed that at early stages of the disease, the virus was exclusively found in the pillar cells and endocardial cells. This indicates that the gills are the most likely port of entry of the virus. It also supports a causal relation between the observed virus and the disease.
\end{abstract}

KEY WORDS: Infectious salmon anemia (ISA) - Transmission of ISA · Infectious route - Virus · Atlantic salmon

\section{INTRODUCTION}

Infectious salmon anaemia (ISA) is a highly contagious and lethal disease which has so far only been reported from fish farms in Norway. The disease is characterized by severe terminal anaemia, stupor, coma and high mortality. Necropsy findings include exopthalmus, ascites, congestion, enlargement of liver

\footnotetext{
•E-mail: geir.totland@zoo.uib.no
}

and spleen, and numerous petechiae (Thorud \& Djupvik 1988, Evensen et al. 1991, Thorud 1991, Dannevig et al. 1993, Speilberg et al. 1995). Although a viral origin and a possible target organ have been indicated for ISA (Hovland et al. 1994, Nylund et al. 1995b, Dannevig \& Falk 1995), the time when infected fish start shedding the virus to their surroundings and the route of infection are unknown, and an understanding of the gross pathology and histopathological changes which might be revealed by a better comprehension of the pathogenesis is still lacking. 
When blood homogenates from ISA-inoculated fish are injected intraperitoneally (i.p.) into healthy fish, most of the fish die after an incubation period of 2 to 5 wk (Thorud 1991, Christie et al. 1993, Nylund et al. 1994). ISA also spreads from inoculated fish to healthy cohabitants held in the same aquarium. Thorud (1991) found that the mortality rate of the cohabitants closely paralleled that of the ISA-inoculated fish, and that the incubation period in both groups was approximately the same, independent of the time of cohabitation challenge. This indicated that the inoculated fish must shed the virus in sufficient amounts to infect the cohabitants long before they show any visible symptoms of ISA. Furthermore, the parallel mortality rates in the 2 groups indicated that the cohabitants were all infected over a short time period. Alternatively, the inoculated fish could have started shedding the virus when they became moribund, with shedding at that point so massive that the incubation period for the cohabitants was substantially reduced. The first aim of the present study was to identify at what time in the incubation period infected fish start shedding the virus.

Transmission of ISA can occur by direct contact between infected and healthy fish, via ectoparasites transferred between individuals, or by contamination of inhabitated water masses (Nylund et al. 1994). The second aim of this study was to determine the importance of the skin mucus, urine and faeces in the waterborne spread of the disease.

The third objective was to describe the localization of the virus - with special emphasis on the early and middle phases of the infection-in different organs/ cells selected on the basis of their proximity to the natural secretions and excretions.

\section{MATERIALS AND METHODS}

Fish. Atlantic salmon Salmo salar L. smolts, weighing from 100 to $500 \mathrm{~g}$, were allowed to adapt for a week in $200 \mathrm{l}$ aquaria in UV-treated seawater at $34 \%$ salinity and a temperature of 7 to $8^{\circ} \mathrm{C}$. The water exchange was approximately $200 \mathrm{l} \mathrm{h}^{-1}$. The fish were fed EWOS dry pellets and normal feeding behavior was observed prior to commencement of each experiment.

Sequential cohabitation challenge during the incubation period. In each trial ( $n=3) 20$ smolts were injected (i.p.) with $0.15 \mathrm{ml}$ of a homogenate of blood (ISA-inoculated group) collected from salmon suffering from ISA. The blood homogenate was prepared according to Christie et al. (1993). Each trial group, consisting of 6 healthy smolts (cohabitants) of the same stock, was challenged for $48 \mathrm{~h}$ in the same aquarium as the ISA-inoculated group. The cohabitant challenges were performed sequentially in the period from Day 3 to Day 17 after the ISA-inoculated group had been infected. After challenge the different groups of cohabitants were kept in separate aquaria and observed for appearance of clinical signs of ISA.

Smolts which survived ISA-inoculation experiments were kept for 2 to 3 mo and were then reinoculated i.p. with blood homogenate. After an additional $50 \mathrm{~d}$, 5 healthy, Floy tagged smolts were put into the same aquarium and observed for development of clinical signs of ISA.

Collection and preparation of excretions and secretions. Two weeks after i.p. inoculation of blood homogenates to smolts, blood, faeces, urine and skin mucus were collected. The fish were anaesthetized with methomidate (5 $\mathrm{mg} \mathrm{l}^{-1}$ seawater) (Mattson \& Riple 1989).

The different excretions or secretions were collected in the following order: urine (non-contaminated by faeces) was collected by gently squeezing the region dorsal to the exit from the urinary bladder ${ }_{i}$ faeces were obtained by squeezing the ventral part of the abdomen in the caudal direction; and skin mucus was collected by scraping a scalpel blade along the lateral sides of the fish. All these samples were transferred to sterile Petri dishes and pooled. Finally, blood was collected from the caudal vein using a heparinized syringe.

In 3 separate trials skin mucus was also collected from fish which had been exposed by cohabitation for $48 \mathrm{~h}$ with an i.p. ISA-inoculated group from Day 15 to Day 17 after inoculation.

The collected skin mucus and faeces were homogenized in a Potter-Elvehjem tissue grinder (size AAA) and centrifuged at $3300 \times g$ for $10 \mathrm{~min}$ at $4^{\circ} \mathrm{C}$, and the supernatant was passed through a membrane filter with a pore size of $220 \mathrm{~nm}$. The urine was diluted 1:1 with PBS (phosphate-buffered saline) before filtration. The blood was centrifuged at $800 \times \mathrm{g}$ for $10 \mathrm{~min}$. Plasma was collected, centrifuged at $10000 \times \mathrm{g}$ for $20 \mathrm{~min}$ and passed through a $220 \mathrm{~nm}$ filter. Blood cells were washed 3 times with MEM (minimum essential medium) prepared with Earle's salts, homogenized, centrifuged at $10000 \times \mathrm{g}$ and filtered through a $220 \mathrm{~nm}$ filter (Christie et al. 1993).

Infectivity assessment of excretions/secretions. I.p. injections: In each trial $(n=3) 10$ healthy smolts were anaesthetized, and injected i.p. with $0.2 \mathrm{ml}$ of skin mucus, faeces, urine or blood homogenate. The fish were then transferred to separate aquaria and observed daily for clinical signs of ISA

Negative control groups received a similar dose of PBS or faeces from non-inoculated smolts.

Gill challenge: This was performed by adding dropwise $0.5 \mathrm{ml}$ of the prepared solutions of urine, faeces or skin mucus to the gill filaments on both sides of anaesthetized fish. Ten fish in each group $(n=3)$ were 
exposed for 4 min, washed in clean water and kept groupwise in separate tanks, and then observed for the development of clinical signs of ISA. Controls were given the identical treatment with PBS.

Introduction into stomach: $0.2 \mathrm{ml}$ of the urine, faeces and skin mucus was introduced through the oesophagus to the stomach via a blunt syringe. Each group ( $\mathrm{n}=$ 3) consisted of 10 fish, marked with Floy tags, which were kept in the same aquarium and observed for development of clinical signs of ISA. Controls were given the identical treatment with PBS.

Based on these results, the number of days from infection of the fish to $50 \%$ mortality of the fish ( $\operatorname{LT}_{50}$ ) was calculated.

Procedure for estimating the number of virus particles in water. Water samples from an aquarium with ISA-inoculated smolts were collected at the same time each morning before feeding the fish. The samples were preserved immediately in bottles containing glutaraldehyde at a final concentration of $1 \%$.

Copper grids (400 mesh) were attached to a small piece of double-sided tape in the center of a piece of a nitrocellulose filter (Sartorius). The water samples were then filled into flat-bottom centrifuge tubes and each grid attached to the filter was allowed to sink to the bottom. The tubes were balanced so that the water was no more than 2 to $3 \mathrm{~mm}$ from the top of the tubes.

The samples were then centrifuged at $200000 \times g$ for $1 \mathrm{~h}$. The supernatants were removed with a suction pipette and the filters containing the grid were carefully picked up. The grids were then loosened from the tape, stained with $2 \%$ uranyl acetate for 30 s, drained with filter paper, rinsed once by dipping in distilled water and allowed to air dry (Bratbak \& Heldal 1993). They were then observed in a JEOL $100 \mathrm{CX}$ transmission electron microscope at a magnification of $100000 \times$. Virus particles with diameters of about $100 \mathrm{~nm}$ were counted in 50 view fields from each water sample. Bacteriophages were not included in the counting. The water volume from which the virus particles were harvested during the centrifugation was calculated according to formulas given by Bratbak \& Heldal (1993). Each view field had harvested a water volume of $1 \mathrm{nl}$.

Electron microscopical examinations. In a separate experiment, 50 smolts, each weighing from 100 to $150 \mathrm{~g}$, were injected i.p. Five fish each were sacrified on Days $8,11,13,15,18,20$ and 22, respectively. The fish started to die on Day 21. Days 8 and 11 are referred to as the early stage, Days 13,15 and 18 as the middle stage and Days 20 and 22 as the late stage of the incubation period. Control fish from a similar-sized group of cohort smolts were sacrified at the same times.
After anaesthetization all fish were fixed by vascular perfusion for $10 \mathrm{~min}$ via the ventricle of the heart. The fixative consisted of $10 \mathrm{ml} 10 \%$ formaldehyde (newly prepared from paraformaldehyde), $10 \mathrm{ml} 25 \%$ glutaraldehyde, $20 \mathrm{ml} 0.2 \mathrm{M}$ cacodylate buffer and $60 \mathrm{ml}$ PBS, and the $\mathrm{pH}$ was adjusted to 7.35. Samples were taken from the right second gill arch, heart, liver, spleen, head kidney, middle part of the kidney, the fusion of the ureters, urinary bladder, pyloric caecae, intestine, skin and lateral muscle at the crossing point between the lateral line level and anal fin.

Thin sections of each sample were rinsed in buffer and postfixed in $1 \% \mathrm{OsO}_{4}$, dehydrated in ethanol, and embedded in Epon 812. Semithin sections ( $1 \mu \mathrm{m}$ thick) were stained with toluidine blue solution and ultrathin sections were stained in uranyl acetate and lead citrate and observed with a JEOL CX100 transmission electron microscope.

\section{RESULTS}

Necropsy findings in ISA-inoculated smolts revealed identical pathological changes to those observed in natural ISA infections of salmon, i.e. exopthalmus, ascites, congestion, enlargement of the liver and spleen, and numerous petechiae in skin, peritoneum and eyes. In most fish, the liver was yellowish with numerous subcapsular petechial and ecchymotic hemorrhages. The fish were anaemic with pale gill colouring, and hematocrit values below 10 were recorded.

\section{Cohabitation challenge}

In 3 parallel trials ISA-inoculated smolts transmitted ISA with close to $100 \%$ mortality to non-inoculated cohabitants by $48 \mathrm{~h}$ challenge from Day 7 post-inoculation onwards (Fig. 1). The cumulative mortalities were closely parallel for the different cohabitant groups, and the $\mathrm{LT}_{50}$ for the same groups was relatively constant.

Furthermore, smolts which had survived 2 i.p. ISA inoculation experiments for several months transmitted the disease and produced $100 \%$ mortality in the cohort cohabitants. Fish surviving ISA outbreaks may thus act as carrier fish, constituting a reservoir of virus, which is most probably shed continuously into the water.

Counts of virus-like particles from water samples during the incubation period peaked in the early/ middle stage of the incubation period and declined again in the terminal phase of this period (Fig. 2). Bacteriophages were also observed but were not included in the counts (Fig. 3). 


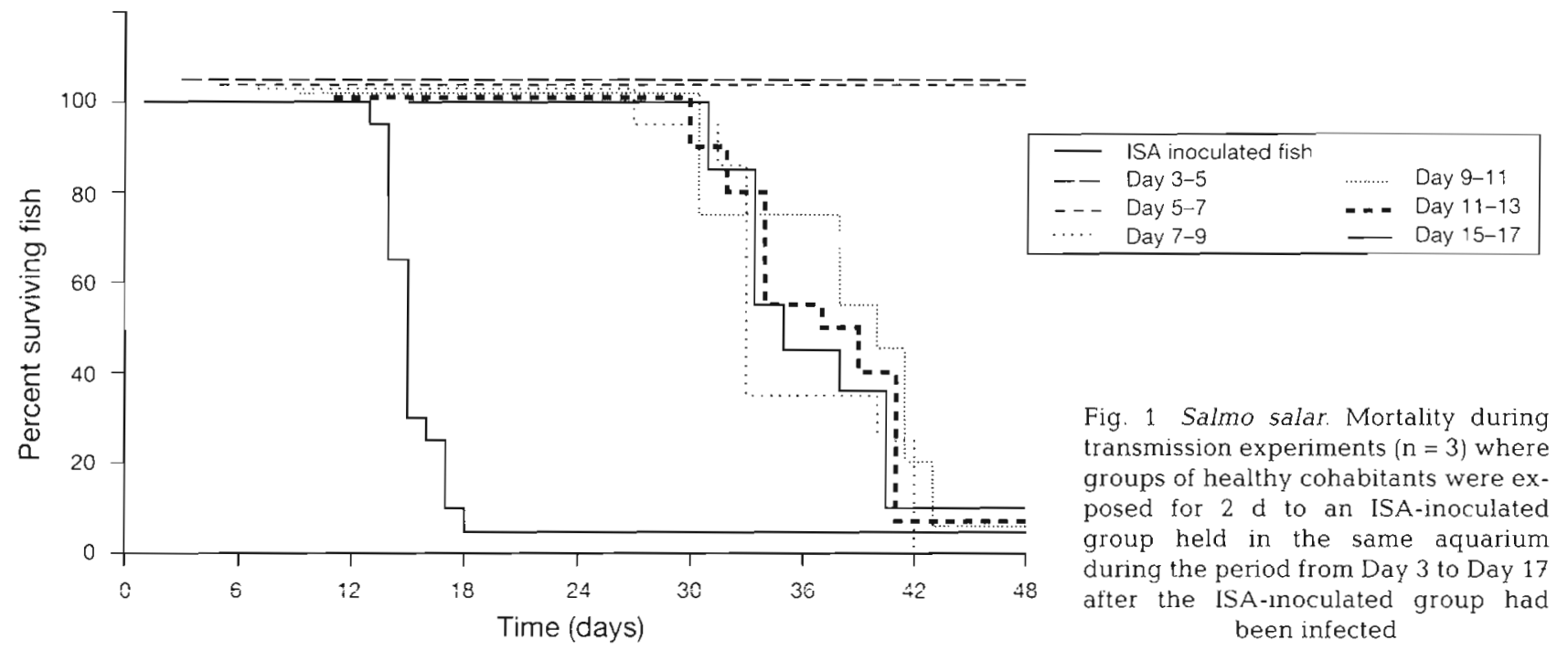

Infectivity of excretions/secretions

The shortest mean $\mathrm{LT}_{50}$ was observed for all infective materials (blood, skin mucus, faeces and urine) when injected i.p. into smolts from the same cohort. Blood homogenates were, in all experiments, the most infective $\left(\mathrm{LT}_{50}=16 \mathrm{~d}\right)$ closely followed by skin mucus $\left(\mathrm{LT}_{50}=\right.$ $18 \mathrm{~d}$ ) and faeces ( $\mathrm{LT}_{50}=18 \mathrm{~d}$ ). Urine from cohabitants also caused mortality but with higher $\mathrm{LT}_{50}$ values (32 d).

When applied to the gills, blood homogenates and skin mucus were less effective in transmitting ISA than i.p. injections of the same preparations. Blood homogenates had the highest infectivity ( $L T_{50}=19 \mathrm{~d}$ ), again closely followed by skin mucus $\left(\mathrm{LT}_{50}=21 \mathrm{~d}\right)$. Urine and faeces revealed higher $L_{50}$ values, 28 and $31 \mathrm{~d}_{\text {, respectively }}$

When introduced into the stomach, neither blood skin mucus, faeces nor urine from ISA-inoculated smolts caused any mortality attributable to ISA in 3 consecutive trials.

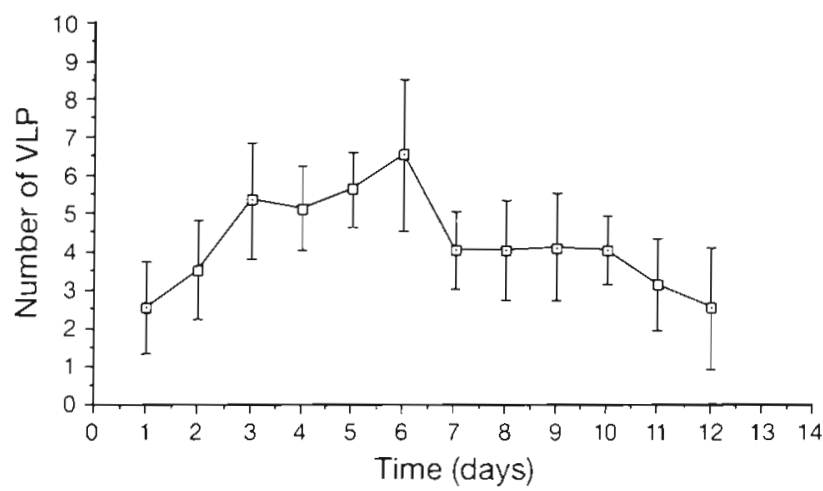

Fig. 2. Mean number of virus-like particles (VLP) per $10^{-7} \mathrm{mI}$ of water sample. The water samples were taken each morning from an aquarium with ISA-inoculated Salmo salar smolts during the incubation period
Skin mucus from uninoculated cohabitants which had been exposed to an i.p. inoculated group for $2 \mathrm{~d}$ (from Day 15 to 17 after inoculation) transmitted the disease with close to $100 \%$ efficiency to healthy smolts from the same cohort when injected i.p. The $\mathrm{LT}_{50}$ was somewhat higher than for skin mucus collected from the i.p. inoculated group, 30 and 34 d respectively, while the $\mathrm{LT}_{50}$ of the group inoculated i.p. with faeces was $38 \mathrm{~d}$.

\section{Electron microscopical observation}

In the early stage of the incubation period, virus particles were detected exclusively in the pillar cells of the gills and endocardial cells of the heart. Viruses were detected in the pillar cells by Day 7 after challenge. Most of the viruses were seen budding off the luminal side of the pillar cells (Fig. 4), while only a few were ob-

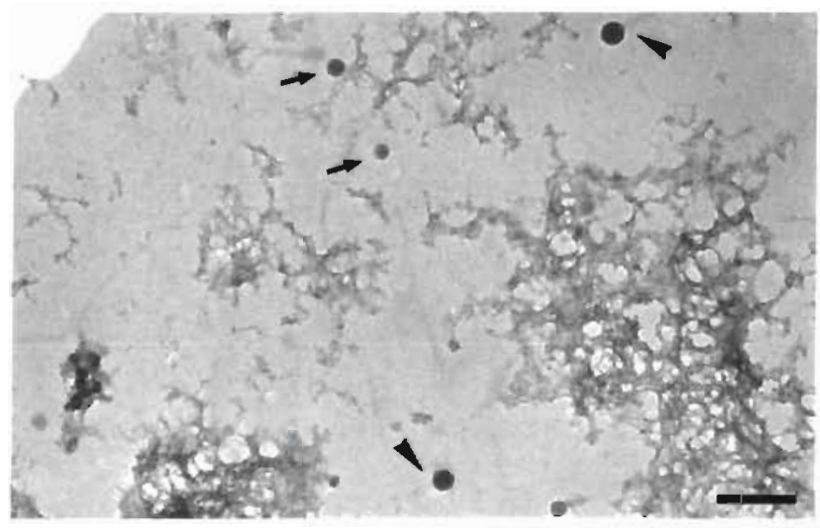

Fig. 3. Part of view field where virus-like particles (arrows) from water in an aquarium with ISA-infected Salmo salar have been harvested by centrifugation. Note that tails of bacteriophages (arrowheads) can be discerned. Scale bar $=0.5 \mu \mathrm{m}$ 


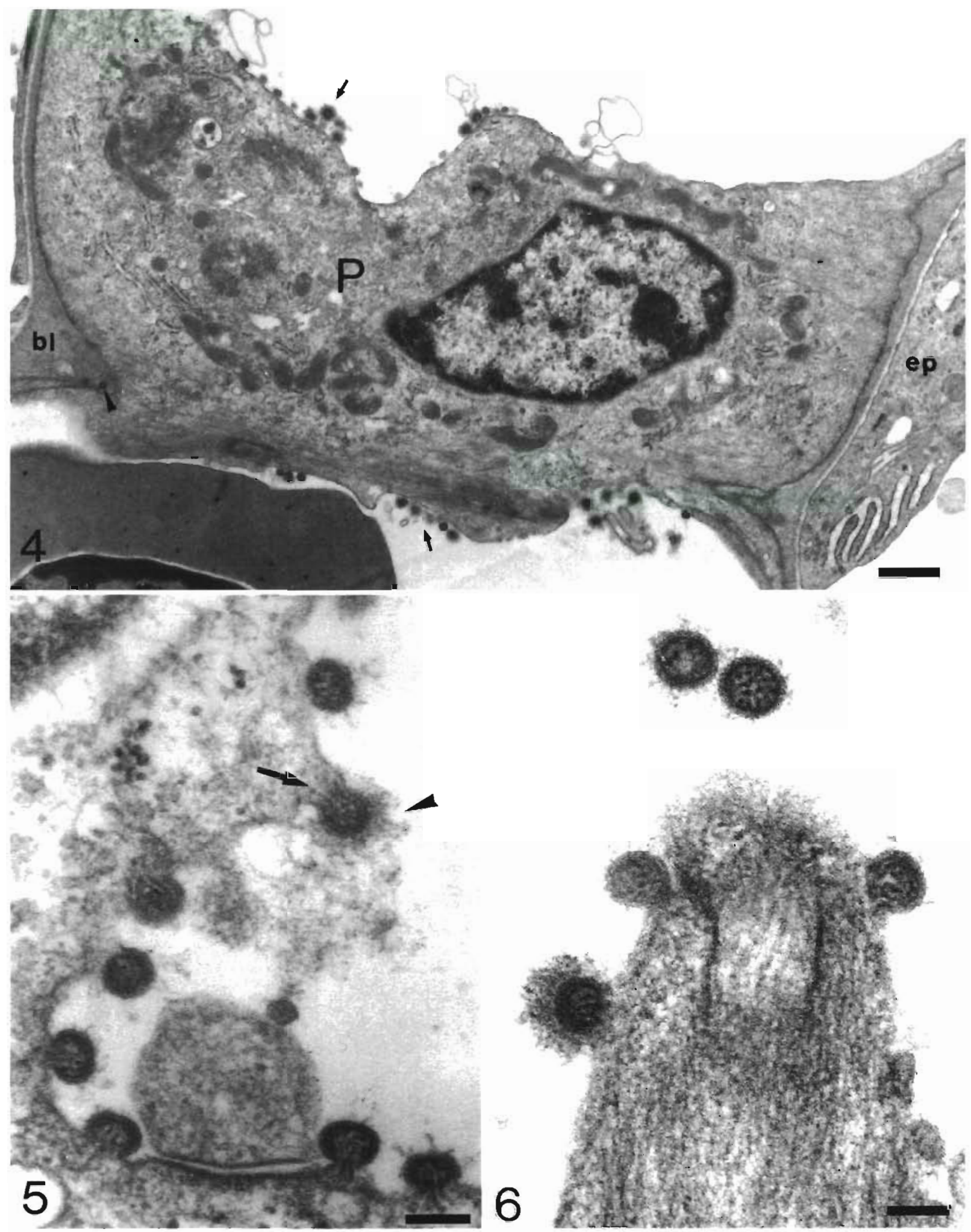

Figs. 4 to 6 . Virus particles from ISA-infected Salmo salar. Fig. 4. Electron micrograph of infected pillar cell (P) in an early stage of the infection, showing numerous virus particles on the luminal sides (arrows). Note the prominent basal lamina (bl) between the pillar and the epidermal cell (ep). One virus can be observed in the basal lamina (arrowhead). Scale bar $=1 \mu \mathrm{m}$. Fig. 5 . Electron micrograph of virus particles budding of from the luminal side of a pillar cell in the gill. Note the distinct coat outside the virus membrane (arrowhead) and arrays of small, electron-dense granules in the area between the virus particle and the host cell (arrow). Scale bar $=100 \mathrm{~nm}$. Fig. 6. Electron micrograph of free virus particles and virus particles budding off from a pillar cell.

Note that the electron-dense granules inside the free virus particles seem to form a regular pattern. Scale bar $=100 \mathrm{~nm}$ 
served in the basal luminas of the epithelial cells (Fig. 4, arrowhead). The virus particles most often formed clusters at the surface of the endocardial cells, and budding of virus particles seemed to occur less frequently than in the pillar cells. In the middle stage, viruses were also observed occasionally in white blood cells and in rare cases even in erythrocytes. In late stages, viruses could also be detected in some leucocytes and in the endothelial cells of some of the blood vessels in the spleen, head kidney and red part of the lateral muscle. In general, relatively few observations of viruses were made even in the late stages of the incubation period

The morphology of the virus revealed identical characteristics in all stages during the incubation period. The virus has a spherical shape (mean diameter about $100 \mathrm{~nm}$ and is surrounded by a unit membrane envelope (Figs. $5 \& 6$ ). The external surface of the membrane envelope is covered by a prominent outer layer of variable density and thickness (Figs. $5 \& 6$ ). On the inside of the virus membrane small electron-dense granules (ca $10 \mathrm{~nm}$ in diameter) were observed. These granules formed arrays in the area between the virus particle and the host cell cytoplasm during the budding process (Fig. 5). In free virus particles the granules in some sections formed a regular pattern (Fig. 6).

\section{DISCUSSION}

The present work supports a causal relationship between the presence of virus and the disease. The passage of the causative agent through $0.22 \mu \mathrm{m}$ filters and our electron microscope findings of numerous virus particles in tissues as well as in the inhabitated water mass are in full agreement with the viral origin of ISA as previously indicated by others (Dannevig \& Falk 1994, 1995, Hovland et al. 1994, Nylund et al. $1995 b)$. The morphology of the virus particles is closely similar to that observed in the above-mentioned works. The question of the identity of the electron-dense granules inside the virus particles has been raised (Hovland et al. 1994. Nylund et al. 1995b). From the present work it is evident that the granules (diam. 10 to $12 \mathrm{~nm}$ ) are considerably smaller than ribosomes (diam. ranging from 20 to $30 \mathrm{~nm}$ ) and that they form arrays between the virus and host cell during the budding process. In addition, the observed regular pattern of electron-dense granules in free viruses indicates that they may be nucleocapsids

\section{Cohabitation challenge}

Results indicate an early transmission of the ISA agent, long before the inoculated smolts developed observable clinical signs of the disease. Although it cannot be completely ruled out, the possibility that the virus is transmitted via microhemorrhaging to the natural secretions and excretions thus seems unlikely, because microhemorrhaging is not typically found in the early prodromal phase of ISA and considerable caution was taken in the preparative procedures to avoid blood contamination of the samples. Furthermore, the high exchange rate of water in the aquaria suggests that either minimal amounts of virus are enough to ensure infection or that there is a massive shedding of virus from the inoculated fish into the water. Although we do not know the identity of the virus detected in our water sample analyses, the peak value in the early and middle stages of the incubation period may favor the hypothesis of massive shedding of virus from the ISA-inoculated smolts.

The other transmission experiment with the smolts which had survived 2 i.p. ISA inoculations shows that virus is replicated continuously in the fish and reveais that seemingly healthy smolts may be carrier fish, and may act as a reservoir of virus which is shed for a long period of time. A similar condition has been reported in brown trout which became carrier fish, shedding virus continuously into the water (Nylund et al. 1995a) following an i.p. injection of a blood homogenate from ISA-infected salmon

\section{Route of shedding of infectious material}

The highly efficient transmission of ISA via skin mucus is interesting but difficult to evaluate. The virus found in skin mucus may originate from mucusproducing cells in the epidermis or it may be absorbed from the surrounding water. By transmission electron microscopy, we were only able to detect virus in leucocytes in some dermal vessels during the late stages of ISA and not in any of the other skin cell types. Microhemorrhages in the skin were not detected in either the early or middle stages of the incubation period for ISA-inoculated smolts. Furthermore, the fact that the skin mucus from cohabitants exposed to ISA inoculated smolts for $48 \mathrm{~h}$ was highly infective indicates that the virus in the skin mucus is absorbed from the surrounding water rather than being produced in the skin. This is also in agreement with the observed peak value of virus-like particles in the water in the middle of the incubation period.

Because of the short exposure time of the cohabitants, eventual transmission of ISA is probably not caused by virus production in the cohabitants but rather reflects waterborne virus which most probably comes from urine and faeces, both of which are infective. There is also a possibility that virus may be shed 
via the liquid which lubricates the abdominal organs and cavity. Contrary to the case in most teleosts, this liquid may leave the salmon via 2 different channels connecting the abdominal cavity with the outside: 2 abdominal pores in both sexes and in addition through the gonophor in females (Harder 1975). However, since production of ascites is not an early clinical sign in the development of ISA, we assume this source to be of minor importance

\section{Portal of entry}

The importance of coprophagy in the transmission of ISA has been stressed (Nylund et al. 1994). Our trials showed that skin mucus, faeces or urine from ISAinoculated fish introduced into the stomach did not cause ISA. It is thus concluded that the gastrointestinal passage renders the ISA virus non-infective and accordingly that coprophagy does not transmit ISA under controlled laboratory conditions.

Taking into consideration the short time of exposure to the infectious sources in our experiments, the uptake of virus by healthy smolts must be rather efficient. The most probable portal of entry for the virus into the fish is through the gills, where the total surface area of the secondary gill lamella in smolt is about 20 times larger than that of the total skin area (Hughes 1972). Indeed, the first place virus was found to appear after i.p. challenge was in the pillar cells of the gills. Other thin organs with a large surface area, e.g. the olfactory or lateral line organs, cannot be excluded, but the most likely route of infection, in our opinion, is through the gills.

Since bloodborne transmission of the disease is unlikely, our working hypothesis was that the replication of virus take place in cells where it can easily be transferred to the natural secretions and excretions of the fish, i.e. the target cells are most likely to be found close to the skin mucus, faeces or urine. In the present study the main focus has been on the early and middle stages of the infection. In these stages virus was most frequently seen budding from pillar cells in the gills, but a few budding figures were also observed from the endocardial cells. In the later stages, virus occasionally was also found in the endothelial cells of some of the larger vessels and in blood cells. It is a paradox in our study that while virus primarily seems to be shed through urine and faeces, we were not able to detect virus particles in any of the tissues in close proximity to the gastrointestinal system or urinary system during the early and middle stages of the incubation period The way in which the viruses enter the urine and faeces thus needs further elucidation.

\section{LITERATURE CITED}

Bratbak G, Heldal M (1993) Total count of viruses in aquatic environments. In: Kemp PF, Sherr BF, Sherr EB, Cole JJ (eds) Handbook of methods in aquatic microbial ecology Lewis Publishers, Boca Raton, FL, p 135-138

Christie KE, Hjeltnes B, Uglenes, I, Winton JR (1993) Determination of buoyant density and sensitivity to chloroform and freon for the etiological agent of infectious salmon anaemia. Dis Aquat Org 15:225-228

Dannevig BH, Falk K (1994) Atlantic salmon, Salmo salar L. develop infectious salmon anaemia ([SA) after inoculation with in vitro infected leucocytes. J Fish Dis 17:183-187

Dannevig $\mathrm{BH}$, Falk K (1995) Isolation of the casual virus of infectious salmon anaemia (ISA) in a long-term cell line from Atlantic salmon head kidney. $J$ Gen Virol 76 $1353-1359$

Dannevig BH. Falk K, Krogsrud J (1993) Leucocytes from Atlantic salmon, Salmo salar L., experimentally infected with infectious salmon anaemia (ISA) exhibit an impaired reponse to mitogens. J Fish Dis 16:351-359

Evensen 0 . Thorud KE, Olsen YA (1991) A morphological study of the gross and light microscopic lesions of infectious anaemia in Atlantic salmon (Salmo salar). Res Vet Sci $51: 215-222$

Harder W (1975) Fish anatomy, Vols I-ll. Paul Parey, Hamburg

Hovland T, Nylund A. Watanabe K, Endresen C (1994) Observation of infectious salmon anaemia virus in Atlantic salmon, Salmo salar L. J Fish Dis 17:291-296

Hughes GM (1972) Morphometrics of fish gills. Resp Physiol $14: 1-25$

Mattson NS, Riple TH (1989) Methomidate, a better anesthetic for cod (Gadus morhua) in comparison with benzocaine, MS-222, chlorobutanol, and phenoxyethanol. Aquaculture 83:89-94

Nylund A, Alexandersen S, Rolland JB, Jakobsen P (1995a) Infectious Salmon Anemia Virus (ISAV) in brown trout. $\mathrm{J}$ Aquat Anim Health 7:236-240

Nylund A, Hovland T, Hodneland K, Nilsen F, Lovik P (1994) Mechanisms for transmission of infectious salmon anaemia (ISA). Dis Aquat Org 19:95-100

Nylund A, Hovland T, Watanabe K, Endresen C (1995b) Presence of infectious salmon anaemia virus (ISAV) in tissues of Atlantic salmon, Salmo salar L., collected during three separate outbreaks of the disease. J Fish Dis 18:135-145

Speilberg L, Evensen Ø, Dannevig BH (1995) Sequential study of the light and electron-microscopic liver-lesions of infectious-anemia in Atlantic salmon (Salmo salar L.) Vet Pathol 32:466-478

Thorud K, Djupvik HO (1988) Infectious anaemia in Atlantic salmon (Salmo salar L.). Bull Eur Ass Fish Pathol 8:109-110

Thorud KE (1991) Infectious salmon anaemia. Transmission trials, hematological clinical, chemical and morphological investigations. PhD thesis, Norwegian College of Veterinary Medicine, Oslo

Manuscript first received: September 21, 1995

Revised version accepted: January 17, 1996
Responsible Subject Editor: F. M. Hetrick, College Park Maryland, USA 